\title{
Population characteristics and influencing factors of terrestrial earthworms in Qinling Mountains
}

\author{
Jian Wang ${ }^{1,2^{*}}$, Chenxi Yang ${ }^{1,2}$, Jingsi Li $^{1,2}$ \\ ${ }^{1}$ Institute of Land Engineering and Technology, Shaanxi Provincial Land Engineering Construction Group Co., Ltd., Xi'an Shaanxi \\ China \\ ${ }^{2}$ Key Laboratory of Degraded and Unused Land Consolidation Engineering, the Ministry of Nature and Resources, Xi'an Shaanxi China
}

\begin{abstract}
Earthworms can have an important effect on a variety of processes that determine soil fertility and play a very important role in natural ecosystems. The biomass and density of earthworms in 4 different land utilize types in the Qinling mountains were investigated using the wet funnel method. The relationship between the characteristics of earthworm populations characteristics and environmental factors were analysed, and the significant differences in soil earthworm density $(P<0.05)$ and fresh weight $(P<0.05)$ were discovered under different land utilize types, and all showed the highest value in orchard land, followed by woodland and grassland, in addition, the lowest was discovered in cultivated land. In addition, Pearson correlation analysis indicate that soil earthworm population characteristics was strongly negatively correlated with soil ammonium nitrogen $\left(\mathrm{NH}_{4}{ }^{+}-\mathrm{N}\right)$, and strongly positively correlated with fine root biomass. The clarified relationship between earthworm population characteristics and soil physical and chemical properties will help qualitatively predict and evaluate the ecological functions of terrestrial earthworms in Qinling mountains.
\end{abstract}

Keywords: Terrestrial Earthworms, Land Utilize Types, Soil Physical and Chemical Properties, Qinling Mountains

\section{Introduction}

As one of the most active soil animal groups in the formation of soil biological fertility, soil animals are not only the objects of protection but also important biological resources that can be used in the process of land use. Earthworms, as large animals in soil, belong to Annelida, Oligochaaeta, and Opithopora [1]. They play an extremely important role in organic matter decomposition, nutrient cycling and soil formation. They regulate soil material circulation and energy conversion processes through activities such as feeding, digestion, excretion, secretion, and burrowing, and are called "ecosystem engineers" [2]. Changes in land use patterns often lead to changes in the community structure of earthworms, and even lead to the invasion of alien species and the disappearance of native species of earthworms [3]. It can cause changes in microbial biomass and activity [4], change soil physical and chemical properties [5], and even cause plant community degradation [6].

Qinling Mountains is an important forest distribution area in my country. The forest area accounts for $75.2 \%$ of its total area. It is an important water conservation area in central my country and has extremely important functions in soil conservation and water conservation. However, since the 1970s and 1980s, due to intense human activities, the natural vegetation has been severely damaged, the landscape fragmentation degree is high, and the natural forest has been replaced by farmland, grassland and shrubs [7]. At present, the research on the characteristics of earthworm populations and their relationship with soil environment under different land use patterns in this area is still blank, and the influencing factors are still unclear. Based on this, this study selected four common land use types in the Qinling Mountains, namely cultivated land, garden land, forest land, and abandoned land. Using a combination of field investigation and biostatistical analysis, the study focused on the characteristics of earthworm populations under different land use types and their relationship with soil environmental factors. The purpose is to provide a theoretical basis for the utilization of soil animal resources and ecological environment protection in this area.

\section{Materials and methods}

\subsection{Overview of the study area}

The survey site is located in Huyi District, Xi'an City, Shaanxi Province, in the southwest of Xi'an City, Shaanxi Province, with Qinling Mountains in the south and Weihe River in the north. The area belongs to the warm tropical

\footnotetext{
* Corresponding author: 574435401@qq.com
} 
semi-humid continental monsoon climate zone in North China, with four distinct seasons of cold, warm, dry and wet. The annual average frost-free period is 219 days, the average precipitation is $879 \mathrm{~mm}$, and the annual average temperature is $13{ }^{\circ} \mathrm{C}$. Light, heat, and water resources are abundant, showing the alternation of wet and dry seasons. In Huafeng Village, Huyi District, Xi'an City, Shaanxi Province, which is close to the Guanzhong Ring Road, the sample plots were selected according to the actual situation of local land use patterns. There are 4 land use types including cultivated land (corn land), garden land (pear orchard), forest land (secondary forest land) and abandoned land, and 4 plots are selected for each type, with a total of 16 plots .

\subsection{Sampling and measurement}

Using the quadrat combined with freehand separation method, and in August 2020, three representative quadrats were selected from the 16 plots of the above four different types of land use types, and the size of the quadrat was 50 $\mathrm{cm} \times 50 \mathrm{~cm} \times 20 \mathrm{~cm}$ (length $\times$ width $\times$ depth), remove the ground cover, dig with a shovel, carefully break the clods and place them on a white plastic sheet, pick the earthworms by hand, count the body length and fresh weight of the earthworms, and calculate the population density period Adult ratio.

Soil moisture content was determined by drying method; soil $\mathrm{pH}$ was determined by $\mathrm{pH}$ meter (Mi150); soil organic matter was determined by concentrated sulfuric acid-potassium dichromate external heating oxidation method; total nitrogen was determined by concentrated sulfuric acid digestion-semi-trace Kjeldahl method Determination; available phosphorus was determined by sodium bicarbonate extraction molybdenum antimony anti-colorimetric method; available potassium was determined by ammonia acetate extraction-flame photometer method; soil fine root biomass and soil bulk density were determined by drying method

\subsection{Data analysis}

One-way ANOVA and Duncan's multiple comparison method were used to analyze the influence of habitat on earthworm characteristics. When the significance level was greater than 0.05 , it was considered to pass the significance test. The correlation analysis method was used to calculate the Pearson correlation coefficients between earthworm characteristics and soil $\mathrm{pH}$, organic matter content, total nitrogen content, available potassium content, and available phosphorus content. The R language software was used for statistical processing and graphing of data.

\section{Results and analysis}

\subsection{Differences in soil environmental factors under different land use types in qinling mountains}

It can be seen from FIGURE 1 that under different land types, soil ammonium nitrogen $(\mathrm{F}=7.372, \mathrm{P}=0.0168)$ and fine root biomass $(\mathrm{F}=201.1, \mathrm{P}<0.001)$ were significantly different, while other soil physicochemical properties were not significantly different difference (all $P>0.05)$. Soil ammonium nitrogen was the smallest in situ and the largest in cultivated land. On the contrary, soil fine root biomass was the smallest in cultivated land and the largest in garden land.
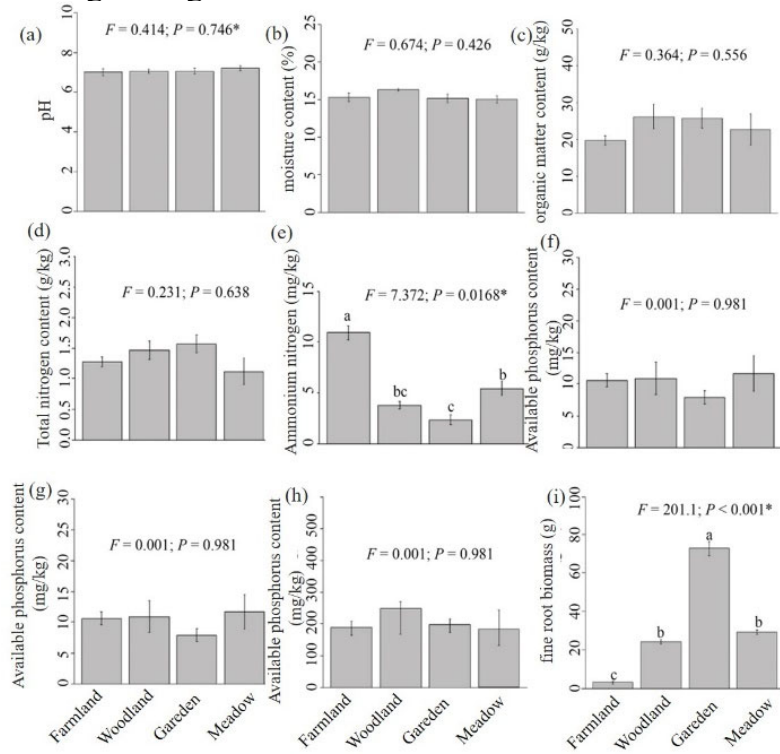

Figure 1. Analysis on the difference of soil environmental factors under different land use types

\subsection{Differences in soil earthworm population characteristics under different land use types in qinling mountains}

It can be seen from FIGURE 2 that there were significant differences in soil earthworm density $(\mathrm{F}=1.17, \mathrm{P}=0.03)$ and fresh weight $(\mathrm{F}=4.651, \mathrm{P}=0.048)$ under different land types. The density of soil earthworms was in the order of garden $>$ woodland \& grassland $>$ cultivated land, and the fresh weight of soil earthworms also showed the order of garden $>$ woodland \& grassland $>$ cultivated land.
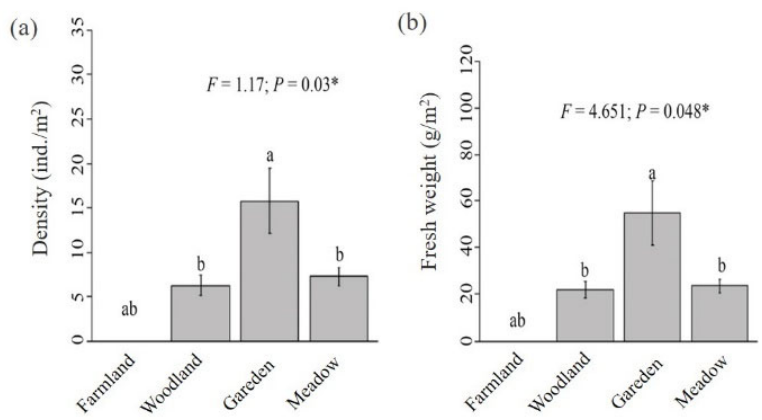

Figure 2. Analysis on the difference of soil earthworm population characteristics under different land use types

\subsection{Correlation analysis between soil earthworm population characteristics and soil environmental factors}

As shown in FIGURE 3, there was a strong positive correlation between soil earthworm population density and earthworm fresh weight; soil earthworm population 
characteristics were strongly negatively correlated with soil ammonium nitrogen, and strongly positively correlated with fine root biomass. In addition, fine root biomass was strongly negatively correlated with soil ammonium nitrogen.

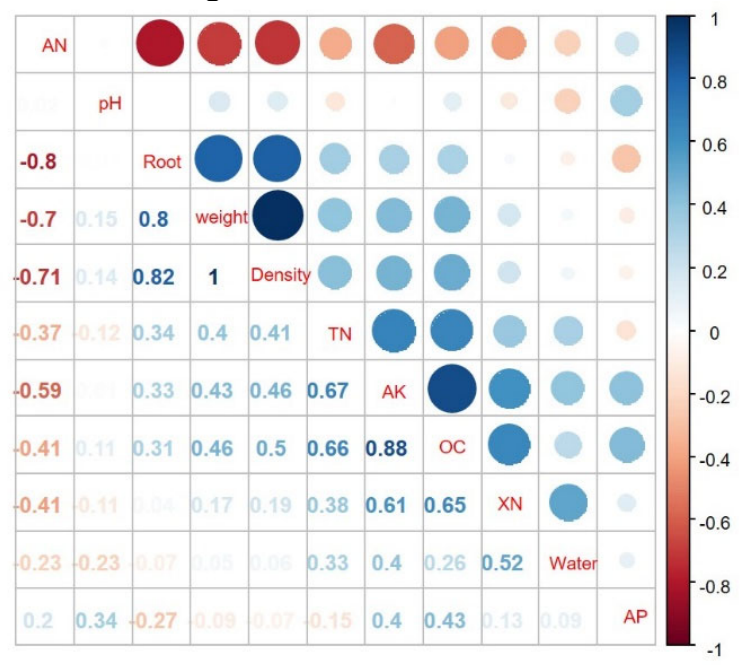

Figure 3. Correlation analysis of earthworm population characteristics and soil environmental factors

\section{Discussion and conclusions}

The soil environment can also affect the diversity of earthworm communities. Previous studies have found that differences in environmental elements will affect the physical and chemical environment of the soil, resulting in changes in the relationship between earthworms and microorganisms and other symbiotic and symbiotic organisms $[8,9]$, which in turn lead to changes in earthworm population density, distribution and other characteristics [10]. Among them, land use, vegetation type and structure are the most important influencing factors. The research on the correlation between earthworm diversity and soil environment mainly focuses on the significant correlation between soil type, texture, farmland crops and earthworm density and biomass. sex. The present study also found significant differences in earthworm population density and fresh weight under different land types, confirming previous studies.

14 native species of earthworms were recorded in Tabasco, Mexico. The individual density and biomass of earthworms were only significantly affected by soil type, but had no significant correlation with other soil factors [11]. In the Palouse prairie wetland in the United States, there is a significant positive correlation between clay content and earthworm density and biomass, and the increase of sand content will significantly reduce the density and biomass of earthworms [12]. In some areas of my country, such as Qianjiang, Hubei, researches on earthworms and soil environment were carried out earlier [13], and then preliminary discussions were also carried out in Handan and Quzhou [14], Liaodong and Jiaodong [15]. There was a very significant positive correlation between earthworm density and soil productivity, organic carbon, total nitrogen, available phosphorus and porosity [16]. A total of 3 earthworm species were recorded in the butterfly-shaped depression of the Sanjiang Plain of Heilongjiang Province, namely the Aisensis chinensis, Norden Aisensis and Harbin Aisensis. The density of earthworms decreased in sequence in island forest, shrub and swamp meadow. The flooding water level and soil moisture content are the key factors affecting the distribution of earthworms in the dish-shaped depression. Meanwhile, the distribution of earthworms is significantly positively correlated with the soil total organic carbon content, $\mathrm{pH}$ and total nitrogen content [17]. These findings reflect the significant effects of dryland soil $\mathrm{pH}$, organic matter, total nitrogen, available phosphorus content and wetland moisture content on earthworm diversity. However, in this study, it was found that soil earthworm population characteristics were only significantly correlated with soil available nitrogen and fine root biomass, but had nothing to do with other soil environmental factors.

In summary, the study found that there were significant differences in soil earthworm density and fresh weight under different land types. All are presented as Garden Land $>$ Woodland \& Grassland $>$ Cultivated Land. There was a strong positive correlation between soil earthworm population density and earthworm fresh weight; soil earthworm population characteristics had a strong negative correlation with soil ammonium nitrogen, and a strong positive correlation with fine root biomass.

\section{Acknowledgments}

This work was financially supported by Shaanxi Provincial Land Engineering Construction Group internal research project (DJNY2021-22) fund.

\section{References}

1. $\mathrm{Xu}$ Qin, Xiao Nengwen. China's terrestrial earthworm [M]. Beijing: China Agricultural Press, 2011.

2. Zhang Weixin, Chen Dima, Zhao Cancan. The role of earthworms in ecosystems [J]. Biodiversity Biodiversity, 2007(2): 38-49.

3. Lavelle, P. (1988). Earthworm activities and the soil system. Biology and fertility of soils, 6(3), 237-251.

4. McLean, MA, Migge-Kleian, S. and Parkinson, D. (2006) Earthworm Invasions of Ecosystems Devoid of Earthworms: Effects on Soil Microbes. Biological Invasions, 8, 1257-1273.

5. Lavelle, P. (1983). The structure of earthworm communities. In Earthworm ecology (pp. 449-466). Springer, Dordrecht.

6. Frelich, L. E., Hale, C. M., Reich, P. B., Holdsworth, A. R., Scheu, S., Heneghan, L., \& Bohlen, P. J. (2006). Earthworm invasion into previously earthworm-free temperate and boreal forests. In Biological invasions belowground: earthworms as invasive species (pp. 35-45). Springer, Dordrecht.

7. Kang Yan. Spatial distribution pattern and ecological conservation strategy of vegetation water conservation function in Qinling Mountains [D]: [Master's Thesis]. Xi'an: Northwest University, 2005. 
8. Bini, D., Santos, CAD, Carmo, KBD, et al. (2013) Effects of Land Use on Soil Organic Carbon and Microbial Pro-cesses Associated with Soil Health in Southern Brazil. European Journal of Soil Biology, $55,117-123$.

9. Li Wei, Cui Lijuan, Zhao Xinsheng, et al. The structure and diversity of soil animal community in Taihu Lake riparian wetlands [J]. Chinese Journal of Ecology, 2013, 35(4): 944-955.

10. Raw, F. (1959). Estimating earthworm populations by using formalin. Nature, 184(4699), 1661-1662.

11. Spurgeon, D. J., Weeks, J. M., \& Van Gestel, C. A. (2003). A summary of eleven years progress in earthworm ecotoxicology: The 7th international symposium on earthworm ecology Cardiff· Wales $\cdot 2002$. Pedobiologia, 47(5-6), 588606.

12. Fragoso, C., \& Lavelle, P. (1992). Earthworm communities of tropical rain forests. Soil Biology and Biochemistry, 24(12), 1397-1408.

13. Bouché, M. B. (1983). The establishment of earthworm communities. In Earthworm ecology (pp. 431-448). Springer, Dordrecht.

14. Zhang Ning, Liao Yan, Sun Fulai, et al. Characteristics of earthworm populations under different land use patterns and their relationship with soil biological fertility [J]. Soil Journal, 2012(2): 162-170.

15. Zhang Yufeng, Wu Yupeng, Sun Qian, et al. Research on earthworm biodiversity in Shandong Peninsula and Liaodong Peninsula [J]. Journal of China Agricultural University, 2014, 19(4): 67-73.

16. Tang Zheng, Li Jiguang, Li Hui, et al. Changes of earthworms and soil fertility under water and fertilizer management mode in facility vegetable fields [J]. Journal of Ecology, 2015(8): 136-140.

17. Cao Siping, Tan Can, Wang Huan, et al. Distribution and influencing factors of terrestrial earthworms in Nanniwan wetlands [J]. Resources and Environment in Arid Regions, 2018, 32(4): 80-84. 